\title{
RULING ISSUED BY THE APPELLATE COURT OF BRESCIA AND ANOTHER CONVICTION FOR THE PRESIDENT, THE DIRECTOR AND THE VETERINARIAN OF GREEN HILL FOR MISTREATMENT AND KILLING
}

On February 23rd, 2016 the Court of Appeals of Brescia confirmed the conviction of three people, the president of Green Hill $2001 \mathrm{srl}$, a big factory of Beagles used for vivisection, the director and the veterinary of the structure. They were convicted to a year and half of detention and the general director was convicted to a year of detention for the mistreatment of 2637 beagles they were breeding and for the illegal killing of 44 beagles. The Court also confirmed the confiscation of all the animals, which are now living with families from all over Italy and convicted them to a two years suspension of activities relating farm animals.

Unnecessary mistreatment and "mass" killings as well as gaps in controls were verified by the Appellate Court, which rejected every defence from the veterinarian that should have taken care of 3000 dogs. Thanks to this historic judgment, necessary justice and equity was confirmed when applying the law to living beings that are capable of suffering and pain and have ethological needs that must be complied with even if an American multinational such as Marshall, has economic interests at stake.

Thus, thanks to this landmark judgment, an unprecedented one because of the number of animals rescued and from a legal point of view, its innovative feature, the "lab-product", "disposable" dog theorem was proven false.

Furthermore, the gaps in the controls by veterinarians of Brescia's ASL (Local Health Unit), clearly emerged during the first instance trial as well as in the Appellate Court. In fact, they will be the subject of a specific trial at the Criminal Court of Brescia (the hearing took place on October 18 ${ }^{\text {th }}, 2016$ ), which involves five defendants in total, including ASL staff and veterinarians. Also, the Public Prosecutor's Office in Brescia has initiated another investigation and trials involving veterinarian staff of Brescia's ASL regarding the violation of animal law: besides Green Hill, other veterinarians were involved in the investigation of the Italcarni slaughterhouse based in Ghedi (BS), where one of the defendants is also undergoing another trial for animal mistreatment, false declaration and failure to report ear cropping and tail docking of adult dogs and puppies which are considered a crime. As civil servants, they are called to ensure adequate controls regarding the respect of animals and legality because of professional deontology and service owed to the State.

\footnotetext{
${ }^{1}$ Attorney at law in Rome and Head of LAV Legal Office.
} 